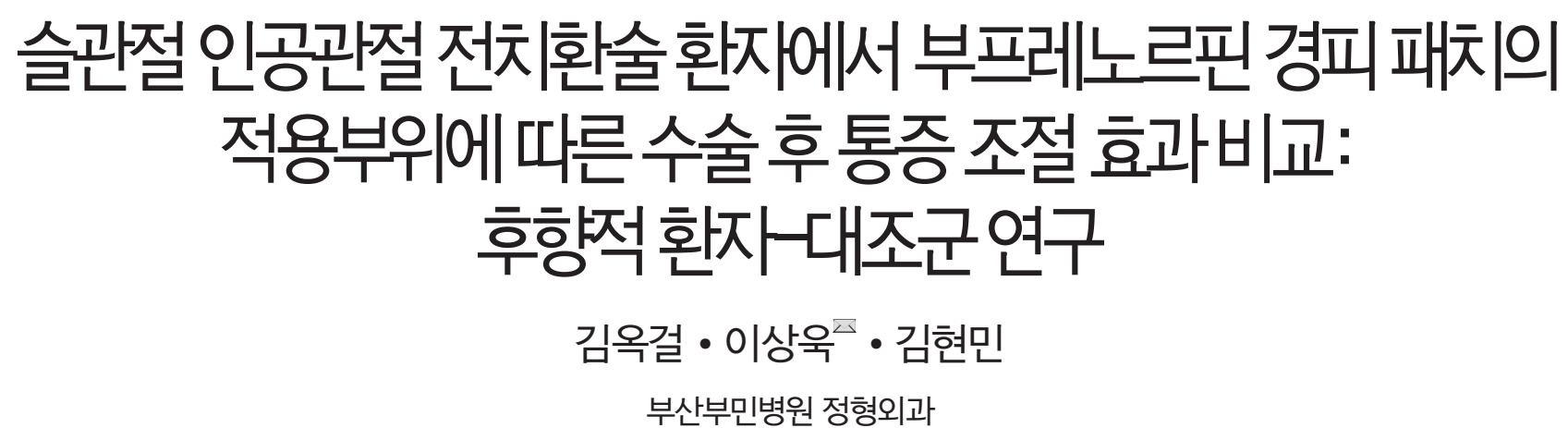

\title{
Comparison of the Postoperative Pain Control Effects of a Buprenorphine Transdermal Patch on Total Knee Arthroplasty Surgery Patients according to Its Applied Sites: Retrospective Case-Control Study
}

\author{
Ok-Gul Kim, M.D., Sang-Wook Lee, M.D. ${ }^{\square}$, and Hyun-Min Kim, M.D. \\ Department of Orthopedic Surgery, Bumin Hospital Busan, Busan, Korea
}

Purpose: This study compared the effects of a buprenorphine transdermal patch (BTDP) on the chest and knee for pain control after total knee arthroplasty (TKA).

Materials and Methods: A retrospective case-control study was conducted from August 2018 to August 2019 on 231 patients who underwent TKA. Two hundred cases were selected considering age, sex, and body mass index. Before and after applying the BTDP, the Numeric Rating Scale (NRS), adverse effects and compliance were measured. All measurements in the chest application group (group $A=100$ ) and knee application group (group $B=100$ ) were compared.

Results: NRS was similar in rest between the groups treated with BTDP, but at two days and three days afternoon, five, six, and seven days postoperatively in group B, the NRS was significantly lower than that of group A. The adverse effects of the central nervous system and gastrointestinal system after applying BTDP were significantly lower in group B than in group A. No significant differences in adverse effects of the cardiovascular system and skin were observed between the two groups. Regarding the maintenance of BTDP, group B was significantly higher than group $\mathrm{A}$.

Conclusion: The direct application of BTDP after TKA to painful knee joints showed excellent results in early postoperative pain control and can be a useful method for increasing patient compliance by reducing the frequency of adverse effects.

Key words: osteoarthritis, postoperative pain, total knee replacement, buprenorphine transdermal patch, periarticular multimodal drug injection

Received November 14, 2019 Revised January 8, 2020

Accepted January 10, 2020

ॠCorrespondence to: Sang-Wook Lee, M.D.

Department of Orthopedic Surgery, Bumin Hospital Busan, 59 Mandeok-daero, Bukgu, Busan 46555 , Korea

TEL: +82-51-330-3000 FAX: +82-51-337-5041 E-mail: osdrwook@gmail.com

ORCID: https://orcid.org/0000-0001-6473-7552

\section{서 론}

슬관절 인공관절 전치환술(total knee arthroplasty, TKA) 후 통 증은 수술 후 재활 지연, 입원 기간의 연장, 반대편 수술에 대한 두려움 등 수술 후 경과에 매우 부정적인 영향을 미친다.1) TKA 
Ok-Gul Kim, et al.

를 받은 환자 중 $60 \%$ 가 Numeric Rating Scale (NRS) ${ }^{21}$ 7-9의 심한 수술 후 무릎 통증을 경험했으며 30\%는 NRS 4-6의 중간 정도의 수술 후 무릎 통증을 경험했다. TKA를 받은 환자는 만족 스러운 수술 결과를 얻기 위해 조기 보행 및 재활을 시작하는 것 이 좋다. 그러나 TKA 후 심한 통증으로 인해 조기 보행 및 재활 이 어려워지며 이는 무릎 경직, 입원 기간의 증가 및 전반적인 환 자 만족도 감소로 이어질 수 있다. ${ }^{3)}$

수술 후 통증 조절을 위해 경구 투약, 경정맥 통증 자가 조절법 (intravenous patient-controlled analgesia, IV-PCA), 말초신 경 차단술(peripheral nerve block, PNB), 관절 주위 다중 약물 투여(periarticular multimodal drug injection, PMDI) 등 다양 한 방법이 시행되고 있다. ${ }^{4}$ 그중 최근 각광받는 방법으로는 PNB 와 PMDI가 있다. ${ }^{5)}$ 하지만 이들은 수술 후 2-3일간 발생하는 급 성기 통증 조절에 국한되어 있어 조기 재활치료가 시작되는 술 후 2-3일 이후의 아급성기 통증을 조절하기에는 제한이 있다.

아급성기 통증 조절은 대부분 약물에 의존하고 있으며 최근 부프레노르핀 경피 패치(buprenorphine transdermal patch, $\mathrm{BTDP}$ ) 등 다양한 패치가 나와 통증 조절에 효과를 보이고 있 다. BTDP 제제는 암을 비롯한 여러 질환에서 만성적 고도의 통 증 조절에 효과가 있는 것으로 알려져 있어 그 처방 영역이 넓어 지고 있다. 정형외과 영역에서도 골관절염과 관련된 만성 통증에 서의 효과 및 근골격계 만성 통증에서 장기간의 ibuprofen, diclofenac의 사용을 대체할 수 있는 대체 제제로서의 효과가 발표 된 바 있다. ${ }^{6-8)}$ 하지만 패치의 흥부 적용으로 인한 중추신경계 및 위장관계 부작용 등으로 인해 중도에 포기하는 환자들이 많은 실 정이며 정형외과 영역에서 적용 부위에 따른 통증 조절 효과 및 부작용에 대한 연구는 아직 미비한 것으로 생각된다.

Khoury 등")의 연구에서 관절공간으로 주입된 오피오이드 (opoid)로부터 진통 효과가 국소적으로 매개될 수 있음을 시사 하는 관절 공간의 활막 내 오피오이드 결합 수용체가 확인되었 다. ${ }^{10)}$ 본 연구에서는 본원에서 TKA을 받은 환자에서 BTDP 적용 부위에 따른 통증 조절 효과 및 부작용 발생 빈도 대해 알아보고 자 하였다. 본 저자는 BTDP 무릎 적용군(B군)이 흥부 적용군(A 군)에 비해 부작용 발생은 줄이면서 통증 조절에 있어 효과적이 라는 가설을 세웠고 이를 확인하기 위해 TKA 후 환자에게 BTDP 를 각각 무릎 관절 주변과 흥부 두 곳에 적용하였다. 수술 후 아급 성기 통증 조절을 위한 BTDP의 효과적인 적용 방법에 대해 알아 보는 것을 본 연구의 목적으로 하였다.

\section{대상 및 방법}

본 후향적 연구는 부산부민병원 임상심사위원회(Institutional Review Board)의 승인하(IRB no. 201911-BM-010)에 진행되 었다. 2018년 8월부터 2019년 8월까지 본원에서 TKA를 시행받
은 환자들 중에서 나이, 성별, 체질량 지수(body mass index) 등 을 고려한 환자-대조군 연구를 위해 선별된 231예를 대상으로 연구를 시행하였다.

본 연구에는 만 55세 이상의 Kellgren-Lawrence 등급 III 이 상, America Anesthesiologists Physical Status 등급 I-III의 골 관절염에 대해 1 차 $\mathrm{TKA}$ 를 시행받은 환자를 포함하였으며, ${ }^{11}$ 최 근 수술 이력(3개월 이내에 반대쪽 무릎 수술, 6개월 이내에 척추 수술)이 있는 20예, 국소 마취제 알레르기가 있는 1예, 지속 작용 아편유사제 치료를 한 만성 통증 이력이 있는 환자 3예, NRS를 이해할 수 없는 환자 2예, 말초신경 차단에 대한 금기 사항(국지 적 감염, 패혈증 또는 기존의 하지신경학적 이상)이 있는 환자 1 예, 패치 부착 후 발생한 합병증(구토, 오심 등)으로 인해 중도 탈 락한 4예 등 총 31예가 제외되었으며 모든 예에서 NRS는 수술 후 1-3일간 하루 두 번, 수술 후 4-7일간 하루 한 번 측정하였으 며 PCA사용량이 누락되어 제외된 예는 없었다.

$\mathrm{TKA}$ 는 한 명의 숙련된 의사에 의해 진행되었다. 모든 환자에 서 척추마취가 시행되었으며 술 전 통증 조절의 목적으로 지속적 인 내전근관 차단술(continous adductor canal block)을 시행 하였고 인공관절 삽입 전에 PMDI를 시행하였다. ${ }^{12)}$ 지속적인 내 전근관 차단술은 척추 마취하에 상전자골극(anterior superior iliac spine)과 슬개골(patella)의 중간 부위에 해당하는 내측 허 벅지에 초음파(LOGIQ P6; GE Healthcare, Milwaukee, WI, USA)를 시행하여 대퇴동맥(femoral artery)과 복재신경(saphenous nerve)을 확인하였다. 초음파 유도하에 바늘을 전진시켜 내전근관 주변의 복재신경에 삽입하였다. 초기 용량으로 $20 \mathrm{ml}$, $0.75 \%$ ropivacaine을 주입한 뒤 지속적인 내전근관 차단술을 위해 20G 카테터(Perfix; B. Braun Melsungen, Melsungen,

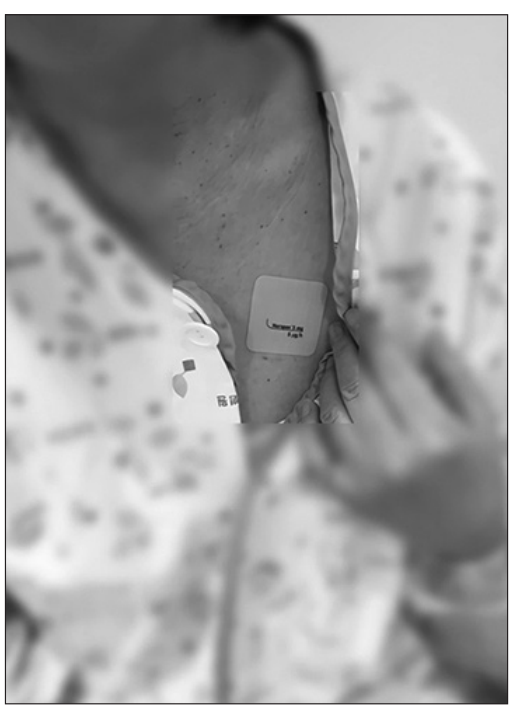

Figure 1. Patch applied on the left chest (chest applied group, group A). 
Germany)를 내전근관 내에 유치시켰다. ${ }^{13)}$ 지속적인 내전근관 차단 술을 위한 주입 펌프 기계는 총 $100 \mathrm{ml}, 0.2 \%$ ropivacaine 이 시간당 $2 \mathrm{ml}$ 씩 들어가도록 하였다.

PMDI 요법(regimen)은 ropivacaine, morphine sulfate, ketorolac, epinephrine (1:1,000), cefuroxime으로 구성되었 다. 수술 중 창상 봉합 전에 준비된 PMDI 혼합물을 외측 측부인 대 주변, 내측 측부인대 주변, 무릎 후 관절낭, 무릎 내측 관절, 거 위발 건초 주변, 슬개인대, 대퇴사두건 그리고 피하조직 내에 주 입하였다. ${ }^{14)}$

모든 환자는 지혈대를 시행하여 내측 슬개 주위 도달법을 통해 후방 십자인대 대치형 $\mathrm{TKA}$ 를 진행하였다. A군은 통증 조절을 위 해 수술 직후 BTDP (Norspan ${ }^{\circledR}$ patch, 5 mg; Mundipharma,

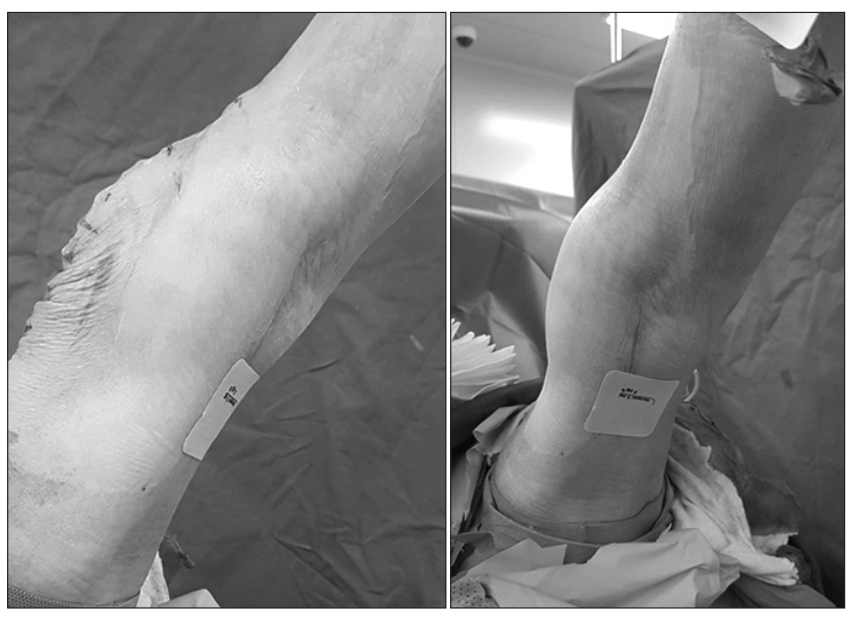

Figure 2. Patch applied above the popliteal wrinkles on the posterior part of the knee (knee applied group, group B).

Table 1. Patient Demographic and Baseline Characteristics

\begin{tabular}{lccc}
\multicolumn{1}{c}{ Variable } & $\begin{array}{c}\text { Chest applied } \\
\text { group }(n=100)\end{array}$ & $\begin{array}{c}\text { Knee applied } \\
\text { group }(n=100)\end{array}$ & p-value \\
Sex (male/female) & $10 / 90$ & $10 / 90$ & $1.000^{*}$ \\
Age (yr) & $75.2 \pm 6.4$ & $74.6 \pm 6.1$ & $0.498^{\dagger}$ \\
Height (cm) & $153.2 \pm 4.2$ & $152.4 \pm 5.2$ & $0.232^{\dagger}$ \\
Weight (kg) & $64.7 \pm 5.3$ & $64.1 \pm 4.9$ & $0.406^{\dagger}$ \\
Hypertension (\%) & 67.0 & 73.0 & $0.356^{*}$ \\
Diabetes (\%) & 68.0 & 66.0 & $0.764^{*}$ \\
KL grade (I/I/III/IV) & $0 / 0 / 22 / 78$ & $0 / 0 / 27 / 73$ & $0.412^{*}$ \\
Preoperative pain (NRS) & $7.5 \pm 1.4$ & $7.4 \pm 1.7$ & $0.716^{\dagger}$ \\
Malalignment & $2 / 98$ & $2 / 98$ & $1.000^{\star}$ \\
(varus/valgus) & & & \\
\hline
\end{tabular}

Values are presented as number only, mean \pm standard deviation, or mean only. ${ }^{\star}$ Chi-square test. ${ }^{\dagger}$ Independent samples t-test. KL grade, Kellgren-Lawrence grade; NRS, numerical rating scale.
Cambridge, UK)를 좌측 가슴에 부착하였다(Fig. 1). B군은 수 술 직후 무릎 후방의 오금 주름의 상방에 $\mathrm{BTDP}$ 를 부착하였다 (Fig. 2). 또한 두 그룹은 수술 후 통증을 관리하기 위해 동일한 IV-PCA를 투여 받았다. IV-PCA에 사용된 진통제는 fentanyl, ketorolac tromethamine, nefopam hydrochloride를 포함하 고 있다. IV-PCA 펌프는 $2 \mathrm{ml}$ 의 로딩 용량, 20 분의 잠금 간격으 로 $0.1 \mathrm{ml} /$ hour의 연속 주입 및 $6 \mathrm{ml}$ 의 1 시간 용량 제한을 두도 록 설정되었으며 필요시 환자에 의해 bolus로 주입하도록 하였 다. IV-PCA는 수술 후 4일째 오전 6시에 제거되었다. 표준 경구 진통제는 12시간마다 celecoxib $100 \mathrm{mg}$, acetaminophen 325 $\mathrm{mg}$, tramadol hydrochloride $37.5 \mathrm{mg}$ 이 투여되도록 구성되었 다. 환자가 추가적인 진통제를 원할 경우 tramadol hydrochloride $50 \mathrm{mg}$ 을 근육 내 주사하였다. 술 후 통증 조절 확인을 위해 1 명의 측정자가 수술 후 1-3일간 하루에 두 번(오전 8시/오후 8 시), 수술 후 4-7일간 하루 한 번(오전 8시) 휴식 시 NRS (신전 상 태)를 측정하였으며 추가적으로 IV-PCA 총량과 추가적인 근육 내 진통제 주사 사용량을 측정하였다. 그 외 BTDP로 인한 부작 용과 첫 BTDP 부착 후 통증 조절 효과가 떨어지는 7일째 환자의 BTDP 재부착 희망 여부를 비교·분석하였다.

통계 분석은 MedCalc (MedCalc ver. 15.2.2; MedCalc Inc., Mariakerke, Belgium)를 사용하여 수행되었다. KolmogorovSmirnov 테스트를 사용하여 측정 및 계산된 매개 변수가 올바르 게 분포되었는지를 확인했으며 독립 샘플 t-검정을 사용하여 연 속 변수에서 그룹 간 차이의 유의성을 결정했다. 카이 제곱 검정 은 두 범주형 변수 사이의 연관을 위해 사용되었다. 모든 결과에 서 0.05 미만의 $\mathrm{p}$ 값을 통계적으로 유의한 것으로 보았다. 검정력 분석(power analysis)은 $\mathrm{T}$-검정을 이용한 두 군의 평균값을 비 교하는 양측 검정에서 효과크기 0.8 , 유의수준 0.05 기준 필요한 각 군의 수가 42 로 확인되어 본 연구의 각 군의 표본수(100예)가

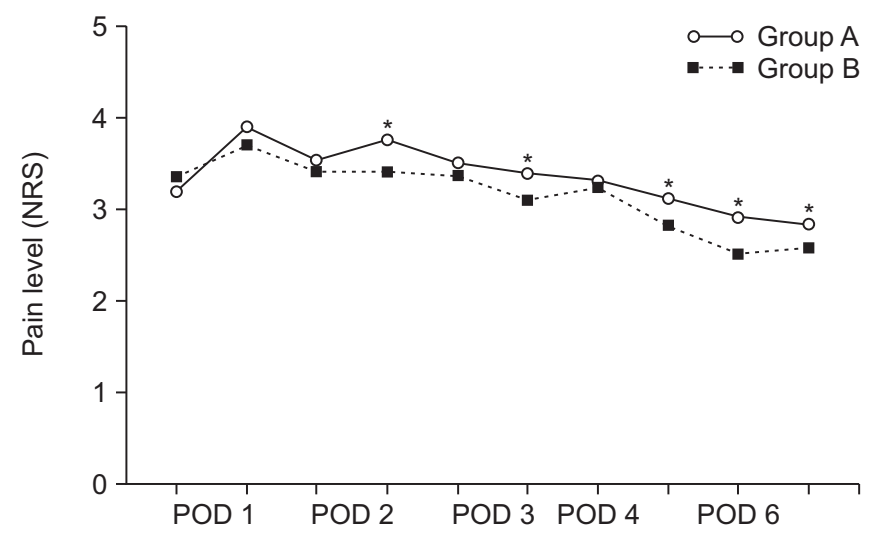

Figure 3. Mean numerical rating scale (NRS) pain score at rest. * $A$ $p$-value $(<0.05)$ was considered significant in the independent samples t-test. Group A, chest applied group; Group B, knee applied group; POD, postoperative day. 
Ok-Gul Kim, et al.

충분함이 확인되었다.

\section{결 과}

연령, 성별, 체질량지수, 수술 전 NRS 점수는 Table 1에 제시되 어 있으며 두 군 간에 서로 유의한 차이는 보이지 않았다. 술 후 $\mathrm{BTDP}$ 적용군 간의 휴식 시 NRS는 전반적으로 비슷하였으나 B 군의 술 후 NRS는 2일째 오후 $3.41 \pm 0.89$ (p=0.013), 3일째 오

Table 2. Comparison of the Adverse Effects between Two Groups

\begin{tabular}{|c|c|c|c|}
\hline Variable & $\begin{array}{l}\text { Chest applied } \\
\text { group }(n=100)\end{array}$ & $\begin{array}{c}\text { Knee applied } \\
\text { group }(n=100)\end{array}$ & $p$-value* \\
\hline Central nerve system & 30 & 3 & $<0.001^{\dagger}$ \\
\hline Somnolence & 4 & 0 & \\
\hline Dizziness & 26 & 3 & \\
\hline Gastrointestinal system & 33 & 5 & $<0.001^{\dagger}$ \\
\hline Vomiting/nausea & 29 & 4 & \\
\hline Dry mouth & 3 & 1 & \\
\hline Constipation & 1 & 0 & \\
\hline Cardiovascular system & 2 & 0 & 0.317 \\
\hline Palpitation & 2 & 0 & \\
\hline Skin & 14 & 22 & 0.141 \\
\hline Dermatitis (urticaria) & 5 & 10 & \\
\hline Irritation & 9 & 12 & \\
\hline General weakness & 14 & 2 & $0.017^{*}$ \\
\hline Other & 0 & 0 & \\
\hline
\end{tabular}

Values are presented as number only. ${ }^{*} \mathrm{~A}$ chi-square test and Fisher's exact test were used. ${ }^{\dagger}$ Statistically significant $(\mathrm{p}<0.05)$.

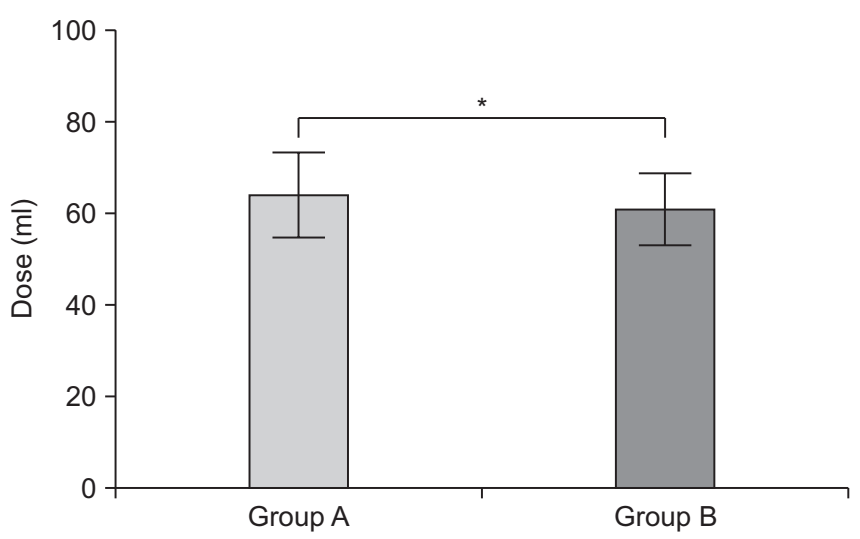

Figure 4. Comparison of the total intravenous patient-controlled analgesia (IV-PCA) amounts between the groups. ${ }^{*} \mathrm{p}$-value $<0.05$ in an independent samples t-test. Group A, chest applied group; Group B, knee applied group.
후 $3.09 \pm 0.96(\mathrm{p}=0.022), 5$ 일째 $2.81 \pm 1.06(\mathrm{p}=0.031), 6$ 일째 $2.51 \pm 1.03(\mathrm{p}=0.012), 7$ 일째 $2.58 \pm 0.59(\mathrm{p}=0.028)$ 로 $\mathrm{A}$ 군의 NRS보다 통계적으로 유의하게 낮았다(Fig. 3). 수술 후 중추신경 계, 위장관계 부작용은 B군에서 유의하게 낮았으며 $(\mathrm{p}<0.001)$, 심혈관계 $(\mathrm{p}=0.317)$, 피부( $\mathrm{p}=0.141)$ 의 부작용은 유의한 차이가 없는 것으로 나타났다(Table 2).

통증 조절을 위한 IV-PCA 총 사용량(Fig. 4)은 A군에서 63.94 $\pm 9.33 \mathrm{ml}, \mathrm{B}$ 군에서 $60.86 \pm 7.78 \mathrm{ml}$ 로 유의하게 낮았으며 $(\mathrm{p}=0.001)$, 지속적인 $\mathrm{BRDP}$ 사용 비율은 $\mathrm{A}$ 군에서 $58.0 \%, \mathrm{~B}$ 군에 서 88.0\%로 $\mathrm{B}$ 군에서 유의하게 높았고( $\mathrm{p}<0.001$; Table 3), 추 가적인 진통제 사용량에서는 $\mathrm{A}$ 군이 $198.12 \pm 66.29 \mathrm{mg}, \mathrm{B}$ 군이 $184.81 \pm 66.19 \mathrm{mg}$ 로 $\mathrm{A}$ 군이 $\mathrm{B}$ 군에 비하여 유의하게 높게 나타 났다(p=0.027; Fig. 5).

\section{고 찰}

이 연구에서 본 저자는 TKA 환자의 수술 후 BTDP 적용 시 NRS 가 두 군 간에 전반적으로 비슷하였으나 B군이 술 후 2,3 일째 오 후와 5, 6, 7일째에 유의하게 낮고 통증 감소에 효과적이라는 것 을 발견했다. 이들 결과는 부프레노르핀의 흡수가 흥부 적용 시

Table 3. Comparison of the Compliance between the Two Groups

\begin{tabular}{cccc} 
Variable & $\begin{array}{c}\text { Chest applied group } \\
(\mathrm{n}=100)\end{array}$ & $\begin{array}{c}\text { Knee applied group } \\
(\mathrm{n}=100)\end{array}$ & $\mathrm{p}$-value \\
Maintenance & & & $<0.001^{\dagger}$ \\
Yes & 58 & 88 & \\
No & 42 & 12 & \\
\hline
\end{tabular}

Values are presented as number only. ${ }^{*} \mathrm{Chi}$-square test was used. ${ }^{\dagger}$ Statistically significant $(p<0.05)$.

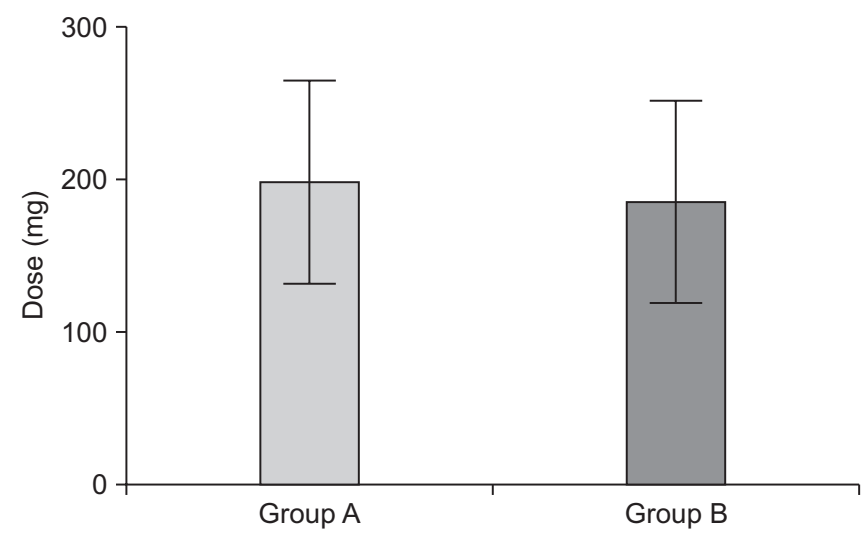

Figure 5. Comparison of the total additional analgesic (tramadol hydrochloride, $50 \mathrm{mg}$ ) amounts between the groups. Group A, chest applied group; Group B, knee applied group. 
에 전신 순환계로 들어갈 때보다 무릎 적용 시 무릎 관절에 존재 하는 국소 오피오이드 수용체에서 더 크기 때문에 통증 조절에 효과적이라고 추측할 수 있게 한다. ${ }^{15)}$ 보존적 치료를 시행하는 슬 관절 골관절염 환자에서 흥부 부착 환자군에 비해 무릎 부착 환 자군에서 효과적인 통증 감소 및 합병증 감소를 보였다는 선행 논문이 있지만 ${ }^{15)}$ 본 논문은 TKA를 시행받은 환자군에서 아급성 기 통증 조절을 위해 $\mathrm{BTDP}$ 를 무릎에 적용하여 연구결과를 도출 한 첫 번째 논문으로서 의의를 가진다고 할 수 있다.

경피 부프레노르핀 제제는 부분적 MU 효능제 및 $\kappa$ (kappa) 길항제로 특징지어지는 마약성 화학적 합성 물질로 적은 전신적 부작용만 가지면서 암성 및 비암성 만성 통증에 강력한 진통 효 과를 보이는 것으로 알려져 있다. 일반적으로 다른 진통제로 조 절되지 않는 심한 근골격계 통증에만 사용하는 것이 추천되어 왔 으며 다른 마약성 진통제보다 적다고는 하나 상대적인 의존 위 험 및 오심, 구토, 변비, 홍반, 가려움증, 식욕저하 등의 부작용도 보고되어 적용의 주의가 요구되고 있다. $\left.{ }^{10}\right)$ 하지만 이러한 부작용 에도 강력한 진통 효과로 최근에 사용이 증가하고 있다. Böhme 등은 만성 근골격계 통증으로 장기간의 경구 ibuprofen 또 는 diclofenac을 복용하고 있는 환자 703명을 대상으로 7일간 의 처방으로 경피 부프레노르핀 제제를 교체 투여하였을 때 임 상적으로 의미 있는 통증 점수의 감소를 보였다고 보고하였으며 Schutter 등ㄱ)은 경구 비스테로이드성 항염증제(non-steroidal anti-inflammatory drugs, NSAIDs) 처방으로 적절한 통증 조 절의 결과를 얻지 못하는 만성 골관절염 환자 4,263 명을 대상으 로 7일 간격으로 처방한 경피 부프레노르핀 제제의 투여로 의미 있는 통증 점수 감소의 결과를 얻었다고 보고한 바 있다.

패치의 적용은 현재 수술 후에 많이 사용되고 있으나 흥부에 부착할 경우 다양한 부작용으로 인해 중도 포기 환자가 많은 실 정이다. 본 연구결과에서도 $42.0 \%$ 가 중도 포기한 것을 확인할 수 있었고 타 논문에서도 비슷한 결과를 보고하였다. ${ }^{16)}$

TKA 후 BTDP 적용의 효과적인 방법에 대해서는 수술 전 10-12시간 전에 부착하는 것이 효과적인 것으로 알려져 있지 만 ${ }^{15)}$ 현실적으로 수술 전에 수술 부위인 무릎에 붙이는 것은 제 한이 많아 본 연구에서는 급성기 통증은 PNB, PMDI로 조절하였 으며 아급성기 통증에 대하여 술 후 흥부 및 수술한 무릎에 적용 하는 방법을 택하였다.

본 연구의 제한점으로는 첫째, 비교적 적은 증례 수의 후향적 연구라는 점이다. 하지만 환자-대조군 연구를 통해 결과를 측정 하고 분석하였으며 한 명의 술자와 숙련된 마취과 의사에 의해 시행되었다는 점에서 편향을 줄일 수 있었다. Power study를 통 하여 충분한 수의 증례를 가졌음이 확인되었지만 추후 더 많은 증례 수를 가지는 전향적 연구가 필요할 것으로 생각된다. 두 번 째, 약물, IV-PCA 등도 통증 조절 및 여러 부작용을 일으킬 수 있 어 BTDP에 의해서만 통증 조절과 부작용이 나타났다고 단정하
기 어렵다는 점이다. BTDP 외의 다른 원인들이 연구결과에 영향 을 줄 수 있기 때문에 이에 대한 추후 연구가 더 필요하다.

\section{결 론}

$\mathrm{TKA}$ 후 BTDP를 통증이 있는 무릎 관절에 직접 적용하는 것은 술 후 통증 조절에 효과적이며 기존의 흥부 적용 방법보다 부작 용의 빈도를 줄여 환자의 순응도를 높여줄 수 있는 유용한 방법 으로 판단된다.

\section{CONFLICTS OF INTEREST}

The authors have nothing to disclose.

\section{ORCID}

Ok-Gul Kim, https://orcid.org/0000-0003-4516-8205 Sang-Wook Lee, https://orcid.org/0000-0001-6473-7552 Hyun-Min Kim, https://orcid.org/0000-0002-1744-7189

\section{REFERENCES}

1. Jeong MS, Song EK, Seon JK, Byun JW, Lee KJ, Jung YW. Effectiveness of pain relief for femoral nerve block in multimodal pain control protocols in total knee arthroplasty. J Korean Orthop Assoc. 2011;46:237-43.

2. Hjermstad MJ, Fayers PM, Haugen DF, et al.; European Palliative Care Research Collaborative (EPCRC). Studies comparing numerical rating scales, verbal rating scales, and visual analogue scales for assessment of pain intensity in adults: a systematic literature review. J Pain Symptom Manage. 2011;41:1073-93.

3. Strassels SA, Chen C, Carr DB. Postoperative analgesia: economics, resource use, and patient satisfaction in an urban teaching hospital. Anesth Analg. 2002;94:130-7.

4. Hirschmann MT, Testa E, Amsler F, Friederich NF. The unhappy total knee arthroplasty (TKA) patient: higher WOM$\mathrm{AC}$ and lower KSS in depressed patients prior and after TKA. Knee Surg Sports Traumatol Arthrosc. 2013;21:2405-11.

5. Paul JE, Arya A, Hurlburt L, et al. Femoral nerve block improves analgesia outcomes after total knee arthroplasty: a meta-analysis of randomized controlled trials. Anesthesiology. 2010;113:1144-62.

6. Sittl R, Griessinger N, Likar R. Analgesic efficacy and toler- 
Ok-Gul Kim, et al.

ability of transdermal buprenorphine in patients with inadequately controlled chronic pain related to cancer and other disorders: a multicenter, randomized, double-blind, placebo-controlled trial. Clin Ther. 2003;25:150-68.

7. Schutter U, Ritzdorf I, Heckes B. [Treatment of chronic osteoarthritis pain: effectivity and safety of a 7 day matrix patch with a low dose buprenorphine]. MMW Fortschr Med. 2008;150 Suppl 2:96-103. German.

8. Böhme K, Heckes B, Thomitzek K. [Application of a seven-day buprenorphine transdermal patch in multimorbid patients on long-term ibuprofen or diclofenac]. MMW Fortschr Med. 2011;152 Suppl 4:125-32. German.

9. Khoury GF, Chen AC, Garland DE, Stein C. Intraarticular morphine, bupivacaine, and morphine/bupivacaine for pain control after knee videoarthroscopy. Anesthesiology. 1992;77:263-6.

10. Hamaguchi S, Ikeda T. [Buprenorphine transdermal patch (Norspan tape)]. Masui. 2013;62:799-807. Japanese.

11. Kellgren JH, Lawrence JS. Osteo-arthrosis and disk degeneration in an urban population. Ann Rheum Dis. 1958;17:38897.

12. Jung WH, Takeuchi R, Chun CW, et al. Efficacy of periartic- ular multimodal drug injection after medial opening-wedge high tibial osteotomy: a randomized, controlled study. Arthroscopy. 2014;30:1261-8.

13. Seo SS, Kim OG, Seo JH, Kim DH, Kim YG, Park BY. Comparison of the effect of continuous femoral nerve block and adductor canal block after primary total knee arthroplasty. Clin Orthop Surg. 2017;9:303-9.

14. Iseki T, Tsukada S, Wakui M, Kurosaka K, Yoshiya S. Percutaneous periarticular multi-drug injection at one day after total knee arthroplasty as a component of multimodal pain management: a randomized control trial. BMC Musculoskelet Disord. 2019;20:61.

15. Gil HY, Park S, Kim NE, et al. A novel application of buprenorphine transdermal patch to relieve pain in the knee joint of knee osteoarthritis patients: a retrospective case-control study. J Clin Med. 2019;8:E1009.

16. Yoon DH, Bin SI, Chan SK, et al. Effectiveness and tolerability of transdermal buprenorphine patches: a multicenter, prospective, open-label study in Asian patients with moderate to severe chronic musculoskeletal pain. BMC Musculoskelet Disord. 2017;18:337. 


\section{슬관절인공관절전치환술환자에서부프레노르핀 경피패치의 적용부위에따른수술후통증 조절 효과비교: 후향적환자-대조군연구 김옥걸 $・$ 이상욱 $・$ 김현민 부산부민병원 정형외과}

목적: 슬관절 인공관절 전치환술(total knee arthroplasty, TKA) 후 통증 조절을 위한 부프레노르핀 경피 패치(buprenorphine transdermal patch, BTDP)의 흥부 적용 및 무릎 적용 효과를 비교하고자 하였다.

대상 및 방법: 2018년 8월부터 2019년 8월까지 TKA를 시행한 231명 중에서 나이, 성별, 체질량 지수(body mass index) 등을 고려한 환자-대조군 연구를 통해 선별된 200예를 대상으로 후향적으로 분석하였다. BTDP를 적용하기 전후에 Numeric Rating Scale (NRS), 부작용 및 순응도를 측정하였으며 흉부 적용군(A군=100명)과 무릎 적용군(B군=100명) 사이의 모든 측정치를 비교 하였다.

결과: 술 후 BTDP 적용군 간의 휴식 시 NRS는 전반적으로 비슷하였으나 B군의 술 후 2, 3일째 오후, 5일, 6일, 7일째 휴식 시 NRS 는 A군의 NRS보다 통계적으로 유의하게 낮았다. BTDP 적용 후 중추신경계, 위장관계 부작용은 B군에서 유의하게 낮았다. 심혈 관계, 피부의 부작용은 두 군 간에 유의한 차이가 없는 것으로 나타났다. 통증 조절을 위한 지속적인 BTDP 유지에서도 B군이 A군 에 비하여 유의하게 높게 나타났다.

결론: TKA 후 BTDP를 통증이 있는 무릎 관절에 직접 적용하는 것은 술 후 초기 통증 조절에 있어 우수한 결과를 보였으며 기존의 흥부 적용 방법보다 부작용 빈도를 줄여 환자의 순응도를 높일 수 있는 유용한 방법으로 판단된다.

색인단어: 골관절염, 수술 후 통증, 슬관절 인공관절 전치환술, 부프레노르핀 경피 패치, 관절 주위 다중 약물 투여

접수일 2019년 11월 14일 수정일 2020년 1월 8일 게재확정일 2020년 1월 10일

책임저자 이상욱

46555 , 부산시 북구 만덕대로 59 , 부산부민병원 정형외과

TEL 051-330-3000, FAX 051-337-5041, E-mail osdrwook@gmail.com, ORCID https://orcid.org/0000-0001-6473-7552 